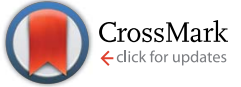

Cite this: RSC Adv., 2017, 7, 2110

Received 10th November 2016 Accepted 13th December 2016

DOI: 10.1039/c6ra26617g

www.rsc.org/advances

\section{Diaminodiacid-based synthesis of macrocyclic peptides using 1,2,3-triazole bridges as disulfide bond mimetics $\dagger$}

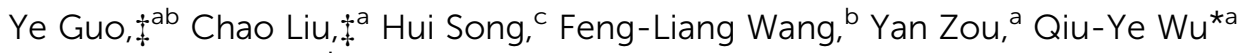 \\ and Hong-Gang Hu*a
}

A new approach for the efficient construction of 1,2,3-triazole bridges as disulfide surrogates in peptides, utilizing the diaminodiacid strategy was established. Two thanatin derivatives were prepared with 1,5and 1,4-disubstituted 1,2,3-triazole diaminodiacids as building blocks. The antibacterial activity studies are also described here.
Disulfide bonds have been shown to play widespread and essential roles in the maintenance of conformational stabilities and biological activities of peptides and proteins. In addition to this, they are indispensable for their thermal stability and their maintenance of protein integrity. As a result, disulfide bonds are called "the switches for protein function" due to their important status. ${ }^{1}$ However, disulfide bonds are prone to degradation in the physiological environment, mainly through reduction, polymerization or enzymatic cleavage, resulting in structural distortion and loss of activity. ${ }^{1 c, 1 g, 2}$

In recent years, great efforts have been made to replace disulfide bonds by synthetic disulfide surrogates, with improved redox stability and structural rigidity, in order to enhance their biological activity and pharmacokinetic properties in vivo. A number of disulfide-bond replacement strategies resulting in great metabolic stability have been employed, including thioether, ${ }^{3}$ olefin ${ }^{4}$ and other bridges. ${ }^{5}$ Nevertheless, tedious synthetic procedures and proper orthogonal protection is inevitable for cystathionine formation, and the ring-closing metathesis (RCM) usually leads to cis/trans isomers during dicarba bridging. ${ }^{3,4}$ On the other hand, additional purification or hydrogenation steps are usually required for the construction of an alkane-based structure with a defined configuration. ${ }^{5 a}$

Benefiting from its chemical orthogonality and its stability against isomerases and proteases, the triazole-based method has attracted much attention in the past few years. ${ }^{6}$ It has

${ }^{a}$ Department of Organic Chemistry, College of Pharmacy, Second Military Medical University, Shanghai 200433, China.E-mail: hhu66@smmu.edu.com; wuqysmmu@ hotmail.com

${ }^{b}$ Department of Pharmacy, Baotou Medical College, Baotou, Inner Mongolia, 014060, China

${ }^{c}$ College of Pharmacy, Weifang Medical University, Weifang, Shandong, 261053, China $\dagger$ Electronic supplementary information (ESI) available. See DOI: $10.1039 / \mathrm{c} 6 \mathrm{ra} 26617 \mathrm{~g}$

\$ These authors contributed equally. already been extensively investigated and applied in peptide chemistry. For instance, the 1,4-disubstituted 1,2,3-triazole was used to properly mimic and rigidify the conformation of the amide backbone. ${ }^{7}$ Various macrocyclizations of peptides were successfully achieved through copper(I)-catalyzed azide-alkyne cycloaddition (CuAAC), both in solution and on solid supports. ${ }^{8}$ Furthermore, the triazole motif has also been widely used as a linking group in carbohydrate chemistry and vaccine preparation. ${ }^{9}$ Therefore, the great chemical and biological compatibility of triazole renders it a wise choice for disulfide-bond replacement. In 2011, Meldal and co-workers described that 1,4-disubstituted 1,2,3-triazoles could be a proper surrogate of disulfide bridges of tachyplesin I, a naturally occurring peptide antibiotic. ${ }^{2 b}$ Soon afterwards, Kolmar et al. explored the utility of a 1,5-disubstituted 1,2,3-triazole group as a disulfide replacement in a monocyclic variant of the sunflower trypsin inhibitor-I (SFTI-1[1,14]) and found that " 1,5 " species could retain the biological activity more effectively compared with "1,4" variants. ${ }^{10}$

However, all of the peptide mimics in the abovementioned reports were synthesized via the post-chain assembly 1,2,3-triazole cyclization strategy (Fig. 1), which caused the potential

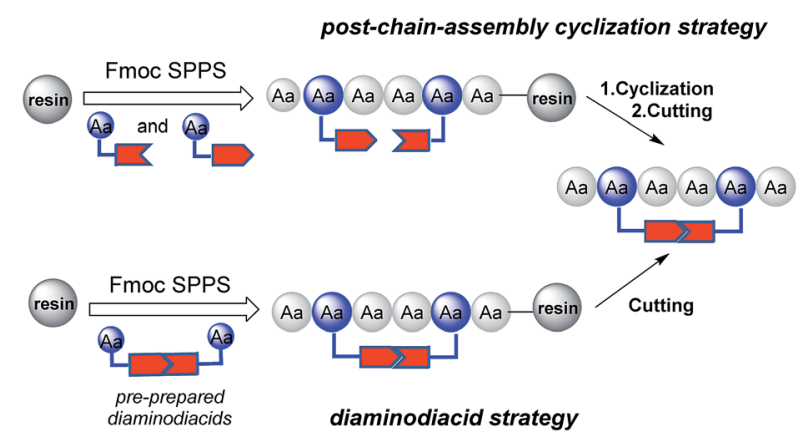

Fig. 1 Two strategies for making disulfide-bond surrogates. 
difficulties of making nonpeptidic bridges on peptides. ${ }^{\mathbf{1 1}}$ First of all, the ruthenium-catalyzed azide-alkyne cycloaddition (RuAAC) reaction, which was used to generate the 1,5-disubstituted 1,2,3-triazole bridge, was found to be either incompatible to solution-phase macrocylization of unprotected peptides or inefficient during SPPS even under harsh conditions (2.1\% yield via microwave irradiation). ${ }^{\mathbf{1 0}}$ Moreover, the postchain strategy may have regioselectivity problems when multiple 1,2,3-triazole units need to be introduced. ${ }^{2 b}$

For these reasons, the construction of peptidomimetics containing single or multiple triazole bridges with both correct conformation and satisfactory output is still challenging. To overcome these shortcomings of the aforementioned synthetic strategy, we are interested in developing a novel strategy based on pre-prepared diaminodiacids for the synthesis of peptide mimics with 1,2,3-triazole as a disulfide surrogate (Fig. 1); this strategy has previously been successfully applied to prepare other peptide disulfide bond mimics. ${ }^{2 a, 11}$ Since every step is achieved via peptide coupling reactions, the difficulty in generating nonpeptidic structures on peptides can be avoided when using this strategy. To explore this new method, thanatin (GSKKPVPIIYCNRRTGKCQRM), a 21-residue macrocyclic antibiotic peptide, was selected as the model peptide. ${ }^{\mathbf{1 2}}$ It has been reported that thanatin adopts a well-defined anti-parallel $\beta$ sheet structure stabilized by one cross-stand disulfide bond. ${ }^{13}$ In the present study, compounds 2 and 3 (Fig. 2) with 1,5- and 1,4-disubstituted 1,2,3-triazole bridges as disulfide replacements were designed and synthesized, respectively, and their anti-bacterial activities were evaluated to investigate the influence of different triazole motifs on thanatin.

Previous studies have shown that diaminodiacids are useful for the synthesis of disulfide-bond surrogates and could be directly applied as building blocks just like mono amino acids. $^{2 a, 11,14}$ To implement the synthesis of peptidomimetics containing two species of the 1,2,3-triazoles group, our efforts began by constructing diaminodiacids were then united into the peptide backbone directly via Fmoc/tBu SPPS (solid-phase peptide synthesis) to obtain the target thanatin derivatives. As shown in Fig. 3, the key diaminodiacids $4 \mathbf{a}$ and $\mathbf{4 b}$ were orthogonally protected with allyl/allyloxycarbonyl (Alloc) groups, which were compatible with the SPPS procedure and could be removed directly on resin using $\left[\mathrm{Pd}\left(\mathrm{PPh}_{3}\right)_{4}\right] / \mathrm{PhSiH}_{3} \cdot{ }^{15}$

To synthesize the diaminodiacids $\mathbf{4 a}$ and $\mathbf{4} \mathbf{b}$, as shown in Scheme 1, 3-amino- $N$-Boc-L-alanine (Boc-Dap-OH, 5) was selected as the starting material. First, $\mathbf{5}$ was transformed into

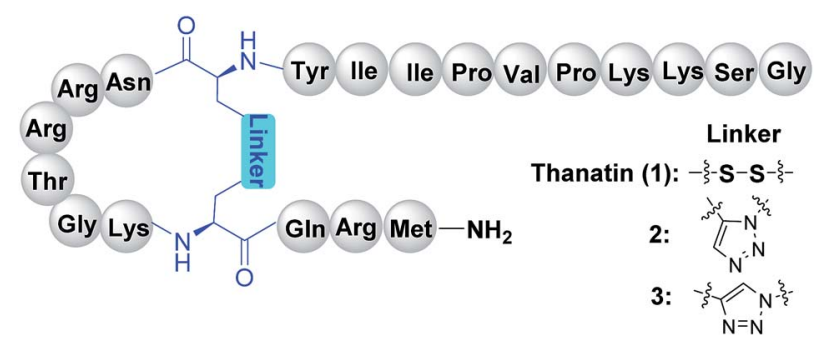

Fig. 2 The target macrocyclic peptides we designed and synthesized.

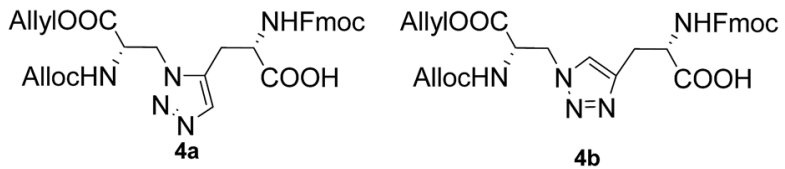

Fig. 3 Structure of diaminodiacid building blocks $4 a$ and $4 b$.

3-azido- $N$-Boc-L-alanine (6) via a $\mathrm{Cu}(\mathrm{II})$-catalyzed diazo transfer reaction with a yield of $73.0 \% .^{16}$ Then, the tert-butoxycarbonyl (Boc) group of 6 was easily cleaved by trifluoroacetic acid, and the free amino acid was further protected with Alloc and allyl groups to afford 7 with a yield of $73.6 \%$. Unfortunately, during the preparation of $\mathbf{4 a}$, compound 7 was found to be incompatible with a ruthenium catalyst. Therefore, compound 8, a substitute with carbobenzyloxy $(\mathrm{Cbz})$ and benzyl $(\mathrm{Bn})$ groups, was generated for the 1,5-disubstituted 1,2,3-triazole building block with a yield of $62.0 \%$ in three steps.

Subsequently, installation of the tert-butyl $(t \mathrm{Bu})$ protective group, followed by capping of the Fmoc group on 2-propargyl-Lglycine (H-Pra-OH, 9) provided Fmoc-Pra-OtBu (10) with a $70.0 \%$ yield in two steps. On one hand, 10 was "clicked" through the $\mathrm{Cp} * \mathrm{RuCl}(\mathrm{COD})$ reaction with $\mathbf{8}$, followed by replacement of $\mathrm{Cbz}$ and $\mathrm{Bn}$ by Alloc and allyl groups to achieve 11 with a yield of $54.7 \%$ in three steps. ${ }^{17}$ On the other hand, 12 could be obtained through the CuAAC reaction between 10 and 7 directly, with an $84.1 \%$ yield. ${ }^{18}$ Finally, the diaminodiacid

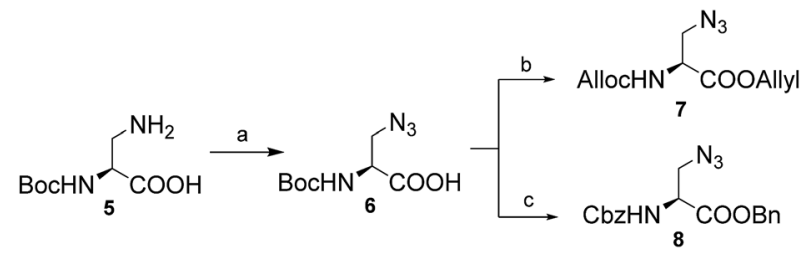

Scheme 1 Reagents and conditions: (a) $\mathrm{TfN}_{3}, \mathrm{CuSO}_{4} \cdot 5 \mathrm{H}_{2} \mathrm{O}, \mathrm{K}_{2} \mathrm{CO}_{3}$, $\mathrm{H}_{2} \mathrm{O} / \mathrm{MeOH} / \mathrm{CH}_{2} \mathrm{Cl}_{2}, 73.0 \%$; (b) (i) $4 \mathrm{M} \mathrm{HCl} / 1$, 4-dioxane; (ii) Alloc- $\mathrm{Cl}$, $\mathrm{Na}_{2} \mathrm{CO}_{3}, \mathrm{H}_{2} \mathrm{O} / \mathrm{CH}_{3} \mathrm{CN}$; (iii) allyl bromide, $\mathrm{NaHCO}_{3}, \mathrm{DMF}, 73.6 \%$ in 3 steps; (c) (i) $4 \mathrm{M} \mathrm{HCl} / 1,4$-dioxane; (ii) $\mathrm{Cbz}-\mathrm{Cl}, \mathrm{Na}_{2} \mathrm{CO}_{3}, \mathrm{H}_{2} \mathrm{O} / \mathrm{CH}_{3} \mathrm{CN}$; (iii) $\mathrm{Cs}_{2} \mathrm{CO}_{3}, \mathrm{BnBr}, \mathrm{DMF}, 62.0 \%$ in 3 steps.

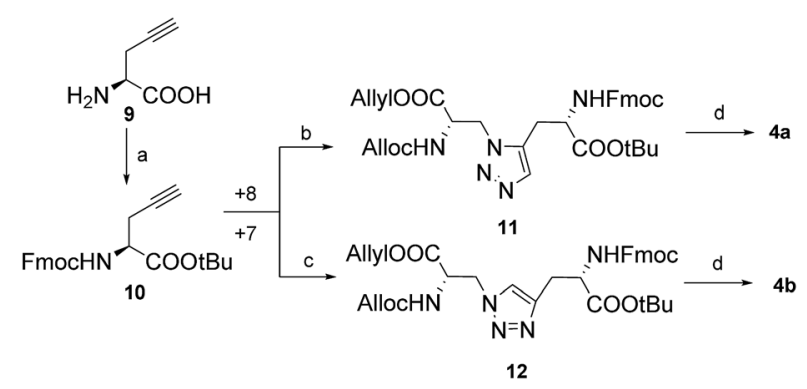

Scheme 2 Reagents and conditions: (a) (i) Fmoc-OSU, $\mathrm{Na}_{2} \mathrm{CO}_{3}, \mathrm{H}_{2} \mathrm{O}$ / 1,4-dioxane; (ii) $t \mathrm{BuOH}, \mathrm{DCC}, \mathrm{DMAP}, \mathrm{DCM}, 70.0 \%$ in 2 steps; (b) (i) 8 , [Cp*RuCl(COD)], DMF, $40{ }^{\circ} \mathrm{C}$; (ii) $\mathrm{H}_{2}, 10 \% \mathrm{Pd} / \mathrm{C}, \mathrm{MeOH}$; (iii) Alloc-Cl, $\mathrm{Na}_{2} \mathrm{CO}_{3}, \mathrm{H}_{2} \mathrm{O} / \mathrm{CH}_{3} \mathrm{CN}$; (iv) allyl bromide, $\mathrm{NaHCO}_{3}, \mathrm{DMF}, 54.7 \%$ in 4 steps; (c) 7, Cul, DIPEA, DMF, 84.1\%; (d) TFA/DCM, 95.0\% for $4 a$ and $96.3 \%$ for $4 b$. 


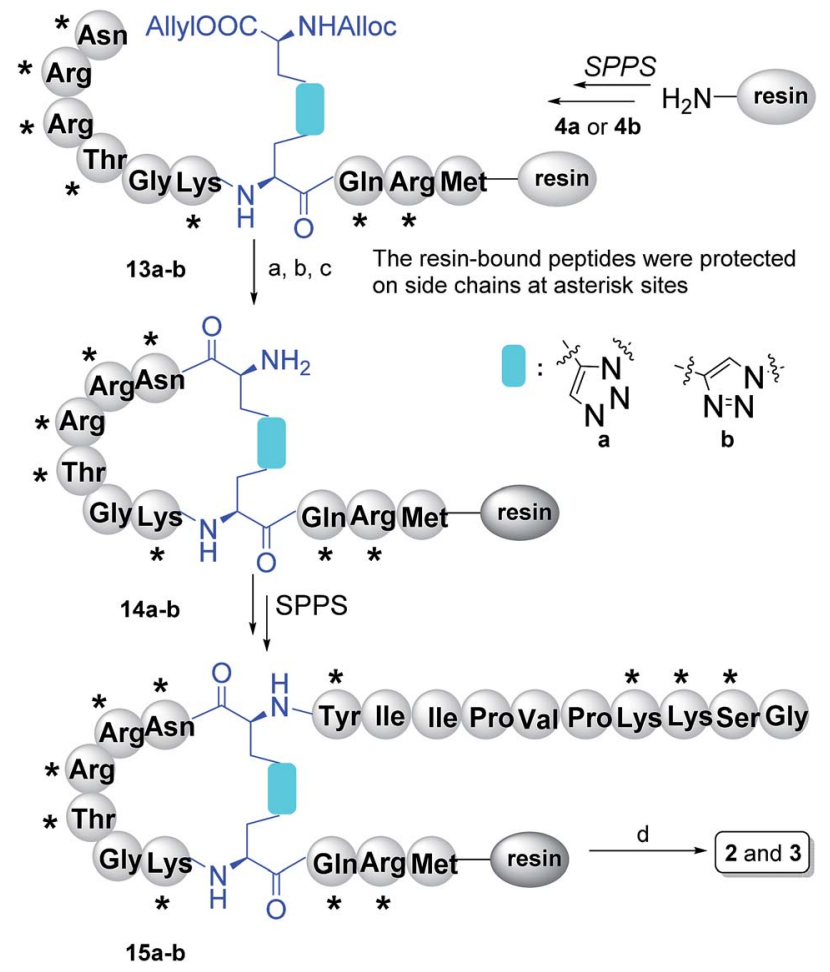

Scheme 3 Reagents and conditions: (a) $\mathrm{Pd}\left(\mathrm{PPh}_{3}\right)_{4}, \mathrm{PhSiH}_{3}$; (b) $20 \%$ piperidine/DMF; (c) PyAOP, HOAt, NMM, NMP; (d) TFA/TIPS/ $\mathrm{H}_{2} \mathrm{O}$ (95: $2.5: 2.5, \mathrm{v} / \mathrm{v} / \mathrm{v}), 29.7 \%$ for 2 and $34.5 \%$ for 3 . The following protecting groups for amino acid side chains were used: tert-butyl ( $t \mathrm{Bu}$; for Thr, Tyr and Ser), 2,2,4,6,7-pentamethyldihydrobenzo-furane-5sulfonyl (pbf; for Arg), tert-butyloxycarbonyl (Boc; for Lys) and trityl (Trt; for Gln, Asn).

building block $4 \mathbf{a}$ or $\mathbf{4 b}$ was prepared from 11 or $\mathbf{1 2}$, respectively, by removing the $t \mathrm{Bu}$ protection group using trifluoroacetic acid; both reactions proceeded with a good yield of up to $95.0 \%$ and $96.3 \%$, respectively (Scheme 2).

The synthesis of the peptidomimetics $\mathbf{2}$ and $\mathbf{3}$ was started from the Rink amide AM resin. The cyclization precursors, linear peptides 13a or 13b were assembled through standard Fmoc/tBu SPPS using HCTU (1-[bis(dimethylamino)methylene]-5chlorobenzotriazolium 3-oxide hexafluorophosphate) as the coupling reagent. ${ }^{19}$ After the cleavage of the protective allyl and Alloc groups via $\left[\mathrm{Pd}\left(\mathrm{PPh}_{3}\right)_{4}\right] / \mathrm{PhSiH}_{3}$, macrocyclization was successfully accomplished with PyAOP ((7-azabenzotriazol-1yloxy)tripyrroli-dino-phosphonium hexafluoro-phosphate), NMM
(N-methylmorpholine) and HOAt (1-hydroxy-7-azabenzotriazole) to achieve the cyclic peptide 14a or 14b. The iterative process was continued by uniting the remaining amino acids to provide side chain protected peptides $\mathbf{1 5 a}$ or $\mathbf{1 5 b}$ on resin. Next, the one step global deprotection and cleavage under acidic conditions was successfully realized to obtain crude compounds 2 and 3 (Scheme 3). Finally, 2 and 3 were obtained following by further purification via reverse phase high-performance liquid chromatography, with a yield of $29.7 \%$ and $34.5 \%$, respectively (according to initial resin load).

With thanatin and its analogues in hand, their antibacterial activities were measured via the MIC (minimal inhibitory concentration) test and summarized in Table 1. Two Grampositive bacteria (Bacillus subtilis and Staphylococcus aureus) and four Gram-negative bacteria (Escherichia coli, Salmonella typhimurum, Klebsiella pneumoniae and Pseudomonas aeruginosa) were grown in the presence of increasing concentrations of three peptides. It was found that the antibacterial activity of thanatin was stronger to the Gram negative bacteria than to the Gram positive bacteria, as previously reported.$^{20}$ Neither of the peptidomimetics showed any anti-bacterial activity up to the peptide concentration of $20 \mu \mathrm{M}$ against any of the bacterial strains except $P$. aeruginosa. Both of the 1,5- and 1,4-disubstituted patterns displayed an inhibitory potency at a concentration of $20 \mu \mathrm{M}$ for $P$. aeruginosa with a reduction $(50.0 \%)$ compared to thanatin. These results may suggest that a nonrigid and flexible linker is indispensable for antibiotic activity in thanatin. It is also important to note that the impact of structurally constrained disulfide replacements, such as 1,2,3triazole bridges, may be dramatically detrimental for its activities in some cases.

To summarize, it was the first time that a diaminodiacidbased strategy was used to introduce 1,5- and 1,4-disubstituted 1,2,3-triazole bridges as disulfide mimics into peptides through SPPS to overcome the difficulties that often occur in post-chain assembly cyclization strategies. Thanatin, a wellstudied antibiotic peptide containing a single disulfide bridge, was chosen as our model. With pre-made 1,5- and 1,4disubstituted 1,2,3-triazole diaminodiacids as disulfide bond surrogates, we showed that these nonpeptidic units could be readily assembled into thanatin at desired sites with a 10 -fold increased yield compared with the previously reported method, particularly for 1,5-disubstituted 1,2,3-triazole substitution. ${ }^{\text {e }}$ The antibacterial test measured via MIC with five bacterial strains indicated that the 1,2,3-triazole derivatives dramatically

Table 1 Minimal inhibitory concentrations (MIC) of thanatin and its analogues against several bacterial strains ${ }^{a}$

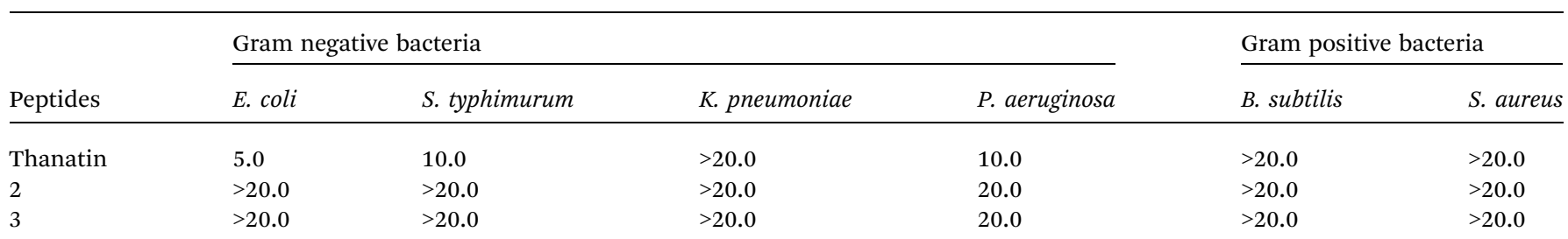

${ }^{a}$ MIC values were measured by standard two-fold dilution protocol and reported in $\mu \mathrm{M}$. 
lost their antibiotic activities. One possible explanation may be that 1,5- and 1,4-disubstituted 1,2,3-triazole bridges, with their rigidity and constrained conformation, may change the bridge length compared with the original backbone. As a consequence, the anti-parallel $\beta$-sheet structure may be distorted, which is significant to its antibiotic activities. To further investigate this problem, experiments towards studying other 1,2,3-triazole bridges containing peptidomimetics, whose pharmaceutical activities are mainly based on $\beta$-hairpin rather than $\beta$-sheet structure, are currently under way. Moreover, the influence of polarity and charge change induced by 1,2,3-triazole bridges should also be investigated.

More significantly, although there was only one pair of 1,2,3triazole bridges introduced into the peptide backbone in the present study, employing properly designed diaminodiacid building blocks with other SPPS compatible protection groups (such as $p$-nitrobenzyloxy carbonyl/ $p$-nitrobenzyl, $\mathrm{pNZ} / \mathrm{pNB}$ ), ${ }^{21}$ tailor-made peptidomimetics containing multiple 1,2,3-triazole bridges can also be achieved through this synthetic approach with good regioselectivity. Profiting from this strategy, the fabrication of peptide mimics with prominent biological activities and pharmaceutical properties may be possible in the future.

\section{Acknowledgements}

We are grateful to the National Natural Science Foundation of China (No. 21402235, No. 21602121) and Instrumental Analysis Center of our university for NMR spectroscopic and mass spectrometric analyses.

\section{Notes and references}

1 (a) J. Gehrmann, P. F. Alewood and D. J. Craik, J. Mol. Biol., 1998, 278, 401-415; (b) J. M. Thornton, J. Mol. Biol., 1981, 151, 261-287; (c) D. L. Rabenstein and K. H. Weaver, J. Org. Chem., 1996, 61, 7391-7397; (d) D. J. Craik, J. S. Mylne and N. L. Daly, Cell. Mol. Life Sci., 2010, 67, 9-16; (e) H. M. Berman, J. Westbrook, Z. Feng, G. Gilliland, T. N. Bhat, H. Weissig, I. N. Shindyalov and P. E. Bourne, Nucleic Acids Res., 2000, 28, 235-242; (f) P. J. Hogg, Trends Biochem. Sci., 2003, 28, 210-214; (g) H. F. Gilbert, Methods Enzymol., 1995, 251, 8-28; (h) R. Wetzel, Trends Biochem. Sci., 1987, 12, 478-482; (i) B. K. W. Chung and A. K. Yudin, Org. Biomol. Chem., 2015, 13, 8768-8779.

2 (a) E. C. Gleeson, Z. J. Wang, S. D. Robinson, S. Chhabra, C. A. Macraild, W. R. Jackson, R. S. Norton and A. J. Robinson, Chem. Commun., 2016, 52, 4446-4449; (b) K. H. Nell and M. Meldal, Angew. Chem., 2011, 123, 53105312; (c) J. Gehrmann, P. F. Alewood and D. J. Craik, J. Mol. Biol., 1998, 278, 401-415; (d) D. L. Rabenstein and K. H. Weaver, J. Org. Chem., 1996, 61, 7391-7397; (e) M. C. A. Laboissiere, S. L. Sturley and R. T. Raines, J. Biol. Chem., 1995, 270, 28006-28009.

3 (a) Z. Dekan, I. Vetter, N. L. Daly, D. J. Craik, R. J. Lewis and P. F. Alewood, J. Am. Chem. Soc., 2011, 133, 15866-15869; (b) J. Bondebjerg, M. Grunnet, T. Jespersen and M. Meldal, ChemBioChem, 2003, 4, 186-194; (c) A. K. Galande,
K. S. Bramlett, T. P. Burris, J. L. Wittliff and A. F. Spatola, J. Pept. Res., 2004, 63, 297-302; (d) P. J. Knerr, A. Tzekou, D. Ricklin, H. C. Qu, H. Chen, W. A. Donk and J. D. Lambris, ACS Chem. Biol., 2011, 6, 753-760.

4 (a) R. F. Nutt, R. G. Strachan, D. F. Veber and F. W. Holly, J. Org. Chem., 1980, 45, 3078-3080; (b) J. Elaridi, J. Patel, W. R. Jackson and A. J. Robinson, J. Org. Chem., 2006, 71, 7538-7545; (c) D. J. Derksen, J. L. Stymiest and J. C. Vederas, J. Am. Chem. Soc., 2006, 128, 14252-14253; (d) C. A. MacRaild, J. Illesinghe, B. J. Lierop, A. L. Townsend, M. Chebib, B. G. Livett, A. J. Robinson and R. S. Norton, J. Med. Chem., 2009, 52, 755-762; (e) A. J. Robinson, B. J. Lierop, R. D. Garland, E. Teoh, J. Elaridi, J. P. Illesinghe and W. R. Jackson, Chem. Commun., 2009, 28, 4293-4295; $(f)$ M. A. Hossain, L. M. HaugaardKedstrom, K. J. Rosengren, R. A. D. Bathgate and J. D. Wade, Org. Biomol. Chem., 2015, 13, 10895-10903.

5 (a) A. K. Galande, J. O. Trent and A. F. Spatola, Biopolymers, 2003, 71, 534-551; (b) M. A. Hossain, K. J. Rosengren, S. Zhang, R. A. Bathgate, G. W. Tregear, B. J. Van Lierop, A. J. Robinson and J. D. Wade, Org. Biomol. Chem., 2009, 7, 1547-1553; (c) T. Luhmann, S. K. Mong, M. D. Simon, L. Meinel and B. L. Pentelute, Org. Biomol. Chem., 2016, 14, 3345-3349; (d) C. M. B. K. Kourra and N. Cramer, Chem. Sci., 2016, 7, 7007-7012.

6 C. W. Tornoe, S. J. Ssanderson, J. C. Mottram, G. H. Coombs and M. Meldal, J. Comb. Chem., 2004, 6, 312-324.

7 (a) Y. L. Angell and K. Burgess, Chem. Soc. Rev., 2007, 36, 1674-1689; (b) A. Brik, J. Alexandratos, Y. C. Lin, J. H. Elder, A. J. Olson, A. Wlodawer, D. S. Goodsell and C. H. Wong, ChemBioChem, 2005, 6, 1167-1169; (c) K. Oh and Z. Guan, Chem. Commun., 2006, 29, 3069-3071; (d) G. M. Williams, K. Lee, X. Li, G. J. S. Copper and M. A. Brimble, Org. Biomol. Chem., 2015, 13, 4059-4063.

8 (a) Y. Angell and K. Burgess, J. Org. Chem., 2005, 70, 95959598; (b) V. D. Bock, R. Perciaccante, T. P. Jansen, H. Hiemstra and J. H. van Maarseveen, Org. Lett., 2006, 8, 919-922; (c) R. A. Turner, A. G. Oliver and R. S. Lokey, Org. Lett., 2007, 9, 5011-5014; (d) V. Goncalves, B. Gautier, A. Regazzetti, P. Coric, S. Bouaziz, C. Garbay, M. Vidal and N. Inguimbert, Bioorg. Med. Chem. Lett., 2007, 17, 55905594; (e) V. D. Bock, D. Speijer, H. Hiemstra and J. H. van Maarseveen, Org. Biomol. Chem., 2007, 5, 971-975; (f) S. K. Agrawal, P. Panini, M. Sathe, D. Choprab and M. P. Kaushik, RSC Adv., 2014, 4, 10728-10730.

9 (a) F. Pessel, I. Billault and M. C. Scherrmann, Green Chem., 2016, 18, 5558-5568; (b) M. Skwarczynski and I. Toth, Chem. Sci., 2016, 7, 842-854.

10 M. Empting, O. Avrutina, R. Meusinger, S. Fabritz, M. Reinwarth, M. Biesalski, S. Voigt, G. Buntkowsky and H. Kolmar, Angew. Chem., Int. Ed., 2011, 50, 5207-5211.

11 H. K. Cui, Y. Guo, Y. He, F. L. Wang, H. N. Chang, Y. J. Wang, F. M. Wu, C. L. Tian and L. Liu, Angew. Chem., Int. Ed., 2013, 52, 9558-9562.

12 P. Fehlbaum, P. Bullet, S. Chernysh, J. P. Braind, J. P. Roussel, L. Letellier, C. Hetru and J. A. Hoffmann, Proc. Natl. Acad. Sci. U. S. A., 1996, 93, 1221-1225. 
13 N. Mandard, P. Sodano, H. Labbe, J. M. Bonmatin, P. Bulet, C. Hetru, M. Ptak and F. Vovelle, Eur. J. Biochem., 1998, 256, 404-410.

14 (a) F. L. Wang, Y. Guo, S. J. Li, Q. X. Guo, J. Shi and Y. M. Li, Org. Biomol. Chem., 2015, 13, 6286-6290; (b) Y. Guo, D. M. Sun, F. L. Wang, Y. He, L. Liu and C. L. Tian, Angew. Chem., Int. Ed., 2015, 54, 14276-14281.

15 Y. C. Huang, Y. M. Li, Y. Chen, M. Pan, Y. T. Li, L. Yu, Q. X. Guo and L. Liu, Angew. Chem., Int. Ed., 2013, 52, 4858-4862.

16 P. B. Alper, S. C. Hung and C. H. Wong, Tetrahedron Lett., 1996, 37, 6029-6032.

17 D. Tietze, M. Tischler, S. Voigt, D. Imhof, O. Ohlenschläger, M. Görlach and G. Buntkowsky, Chem.-Eur. J., 2010, 16, $7572-7578$.
18 X. C. Chen, C. W. Lu, Y. M. Huang and D. V. McGrath, Tetrahedron, 2015, 71, 9154-9160.

19 (a) M. Pan, S. Gao, Y. Zheng, X. Tan, H. Lan, X. Tan, D. Sun, L. Lu, T. Wang, Q. Zheng, Y. Huang, J. Wang and L. Liu, J. Am. Chem. Soc., 2016, 138, 7429-7435; (b) S. Tang, Y. Y. Si, Z. P. Wang, K. R. Mei, X. Chen, J. Y. Cheng, J. S. Zheng and L. Liu, Angew. Chem., Int. Ed., 2015, 54, 5713-5717; (c) J. S. Zheng, S. Tang, Y. K. Qi, Z. P. Wang and L. Liu, Nat. Protoc., 2013, 8, 2483-2495.

20 M. K. Lee, L. Cha, S. H. Lee and K. S. Hahm, J. Biochem. Mol. Biol., 2002, 35, 291-296.

21 A. I. Llobet, J. G. Camell, M. Álvarez and F. Albericio, Eur. J. Org. Chem., 2005, 14, 3031-3039. 